\title{
Ready for the Flipped Classroom? Preliminary Experiences of The New Approach In Teaching Economics to Non-Major Students
}

\author{
Hairong $\mathrm{Mu}^{1}$, Dimitrios Paparas ${ }^{1}$ \\ ${ }^{1}$ Department of Land, Farm and Agribusiness Management, Harper Adams University, Newport, UK \\ Correspondence: Hairong Mu, Department of Land, Farm and Agribusiness Management, Harper Adams University, \\ Newport, TF10 8NB, UK.
}

Received: January 7, 2016

Accepted: January 31, 2016

Available online: February 4, 2016

doi:10.11114/aef.v3i2.1288

URL: http://dx.doi.org/10.11114/aef.v3i2.1288

\begin{abstract}
The flipped classroom is an innovative educational model that has attracted more attention recently. In the flipped classroom, course content is delivered via online videos and/or pre-recorded lectures that can be watched by students at home. It can free up the class time that lecturers are able to devote for learner-centered activities such as problem solving and active learning. This research is motivated by the flipping model with an aim to engage students' learning outside of the classroom as well as respond to the challenges of teaching economics to non-economics majors, which reflect difficulties in delivering all the materials given the limited time period of a class. An online tool called "EDpuzzle" is introduced to facilitate flipping the class. After four-week trial of partially flipping the classroom, we surveyed 170 students from three economics modules to gather their feedback in order to explore the possibility and potential to adopt the flipped classroom strategy at a wider scale. Our pilot analysis indicates that technologies, like EDpuzzle, can help lecturers to deliver the course content through videos and monitor the class, but more effort is needed to motivate and encourage students to participate and prepare. In addition, flipping a class also involves design of various types of activities, including in-class and out-of-class, which are all vital for an effective flipped classroom. Therefore, our study calls for further research on how to design, implement and evaluate the flipped classroom in economics teaching.
\end{abstract}

Keywords: Flipped classroom, online videos, EDpuzzle, active learning, economics teaching

\section{Introduction}

More and more evidence shows that the traditional "chalk and talk" style of teaching in Higher Education (HE) is no longer the most effective way of delivering the course content to students. With the rapid technological changes, students' learning approaches in this electronic age are different from those before. Over the years different teaching strategies and methods have been explored to improve student learning. It has been widely recognized that students are not passive leaners but should be active in their learning process. Various tools have been developed to facilitate the interactive education in the classroom as well as to stimulate the interest and engage students, such as "Digital Ink" (Anderson et al., 2007), "Nearpod" (Curdy, 2015), "Kahoot!" (Mu \& Paparas, 2015) and many others. However, bounded by the limited time available for a class period, lecturers always find it difficult to allocate more time toward in-class activities and discussion. For this reason it has become at the core of the discussion regarding how to allocate class time between lecturing and doing active learning exercises.

Thanks to increased access to the Internet and the wider availability of online videos as well as screen capture technology, it has become entirely possible to shift teaching outside of the classroom through the use of "flipped" learning. According to the definition given by Bishop and Verleger (2013), a flipped classroom "[is] an educational technique that consists of two parts: interactive group learning activities inside the classroom, and direct computer-based individual instruction outside the classroom". Instead of spending all the time in class watching a lecture, students can watch online videos or pre-recorded lectures outside of the classroom at the time and location of their own choice. Then lecturers can allocate more time in class toward opportunities for integrating and applying their knowledge via a variety of active and collaborative learning exercises. Consequently, the flipped learning model can enable lecturers to make the shift from teacher-driven instruction to student-centered learning (Hamdan, McKnight, McKnight, \& Arfstrom, 2013). 
Recently, flipped classroom strategy has attracted increasing attention in the media, Google search and casual hallway chats (Abeysekera \& Dawson, 2015). Despite the popularity of the notion, there is very little evidence of practice or adoption of this approach in economics teaching. Instead, surveys have shown that lecture is still the dominant method for teaching economics (Goffe \& Kauper, 2014).

Although there is lack of evidence to support that flipping a class can enhance economics teaching and learning, the literature reports some commonly mentioned advantages, such as effective use of classroom time, motivation for pre-class assignment, self-paced preparatory work, hands-on class activities and so on (Albert \& Beatty, 2014; Asef-Vaziri, 2015; Kadry \& El Hami, 2014; Prashar, 2015). Therefore, our research is motivated by this new approach to teaching with an aim to engage our students' learning outside of the classroom as well as improve their performance in class. Moreover, our work also contributes to the study of adopting new approach in economics teaching, which seems to have insufficient exploration in practice.

\section{Rationale}

In our university, economics is taught to a wide variety of undergraduate students majoring in Business Management, Food and Consumer Studies, Agri-food Marketing, Agriculture and Agribusiness as part of their program requirements. The vast majority of the students had not studied economics before they came to the university. Due to the lack of prior knowledge, the students have been struggling with understanding the course content. Consequently, the lecturers have to devote most of their class times in explaining the basic concepts, losing the opportunity to explore relevant contexts and let students work on applications of the theory as well as exercises designed to help their comprehension. In addition, students may not gain the same level of understanding while passively listening to lectures, meaning that some of them can get more frustrated and more likely to drop out of their studies.

Ideally, students are expected to prepare outside of the class. As Johnson and Kiviniemi (2009) point out, assigning textbook readings prior to class for undergraduates can be useful to help them understand the content because it is often impossible to present all necessary course material during class time. Since plenty of online videos have become available on the Internet and more attractive to the new generation of students (Sahin, Cavlazoglu, \& Zeytuncu, 2015), assigning videos to watch can also help prepare students before they come to the class.

However, our concern regarding the pre-class preparation is that students often do not complete reading assignment or do not watch videos before the lecture due to insufficient motivation. Online quizzes can be one of the solutions to check on assigned textbook readings (Johnson \& Kiviniemi, 2009). To check on students' completion of assigned online videos, we use an online site called "EDpuzzle" and find it very useful to track students' activities at home, i.e. whether they have watched videos or not. Although some commonly adopted course management software by universities like Blackboard, Moodle or Canvas can do the same job, i.e. tracking students' activities, EDpuzzle has some other features that can better motivate students such as inserting formative assessment anywhere in the videos and providing instant feedback as well as preventing students from skipping content not yet watched. These features are particularly helpful for lecturers to make sure that students have watched all the content required and identify students' varied levels of understanding so that lecturers can tailor lecture content accordingly. In addition, EDpuzzle can also customize the video, i.e. trim the video to use the parts that are most important and needed.

To test the waters of student engagement outside of the classroom and explore the possibility of switching a lecture from a traditional style to a flipped one, we did not flip our class completely, but started the trial with a very small part of each lecture. It is important to gather students' reaction and feedback before wider scale adoption.

\section{Implementation of the trial}

It was hoped that the flipped classroom could engage students' preparation for the lectures and give them more time to understand and digest course content and consequently they would be able to explore relevant contexts and applications. As part of the preparations, we selected the video for each lecture from online sources, i.e. Youtube, which explained some key theory or concept that will be covered in class. The video selected was uploaded to EDpuzzle for editing. For the sake of appreciating the usefulness of this online tool, an instruction of how to use EDpuzzle is given in the next section.

\subsection{Use of EDpuzzle prior to class}

In our study, EDpuzzle was used in three undergraduate economics modules for four-week trial. EDpuzzle is a free online site that allows users to select videos from a wide range of sources, such as YouTube, KhanAcademy, TED and so on, or even upload personal videos for editing. Consequently, it enables lecturers, who consider flipping their classrooms and engaging students learning outside of the classroom, to deliver the content of a course to students by use of videos. One of the very useful features of EDpuzzle is that lecturers can track students' activities, i.e. whether or not they have watched the videos as well as students' answers to the questions inserted anywhere needed in the videos by lecturers. 
To get started, go to EDpuzzle (https://www.edpuzzle.com) and create a teacher account, which is completely free. (Note 1) After signing up, a unique class code will be given, so students can join the class by introducing this code from their account. (Note 2) Clicking on "My Content" will bring the lecturer to the place where all the existing video lessons are stored. From the drop down "Create" menu, the lecturer can choose the videos either by searching various channels using keywords or a URL or by uploading his/her own videos. After reviewing the video, the lecturer can then customize the video with EDpuzzle tools, i.e. "Crop" (trim the video to use those parts you want students to watch) (Note 3), "Audio Track" (add audio clips throughout a video or narrate the entire video to explain the content with personal approach or another language), "Audio Notes" (insert an introductory comment, a conclusion and etc.), and "Quizzes" (insert formative assessment, i.e. open-ended questions or multiple choice questions, anytime during the video). After editing the video, the lecturer can also choose to prevent students from skipping content not yet watched and/or set a due date for students to watch the video.

Once the EDpuzzle lesson is ready, it can be shared with the students and embedded on Moodle or on any webpage. After logging in as a student, students can join a class by entering the unit class code given by the teacher. Once the question is answered, the students have the options to re-watch a part of the video or to continue to the next part. (Note 4)

Furthermore, EDpuzzle makes it easy for lecturers to monitor each class, i.e. whether students have watched each flipped lesson and how many students have answered each question correctly. From our experience, all these features make EDpuzzle a very useful tool to facilitate the flipped classroom. (Note 5)

\subsection{Use of class time}

During the first lecture, we explained how to use EDpuzzle and set expectations about pre-class preparation, i.e. students were required to watch the video (5 to 10 minutes) before each lecture. Students were also told that the video would explain the key theory covered in the lecture.

Since this is a pilot study on flipping a class, we only reserved 15 minutes for each partially-flipped class. The remaining time of the lecture was delivered as normal as in a traditional lecture format.

The first 15 minutes of each lecture was used for clarifying any confusion and misunderstanding of the content in the video, based on the statistics collected from EDpuzzle which enabled the lecturers to identify the areas of weakness and students' varied levels of understanding (Estes, Ingram and Liu, 2014). Rather than to introduce the course materials, the lecturers could devote more time to in-class activities. Some active learning exercises were designed to engage students with the material being covered in the video, for example, we used student response system, i.e. Kahoot! (Mu \& Paparas, 2015), to test students understanding of economic theory and definitions. Moreover, questions and prompts were used to increase student-teacher interaction through group discussion.

\section{Student perceptions toward watching videos before lectures}

In order to assess the trial of the flipped class, at the end of week four, a student survey was conducted in which one hundred and seventy students voluntarily participated. The survey comprised ten questions about student's perceptions toward watching videos prior to class.

The overall feedback on use of EDpuzzle is very positive, i.e. $75 \%$ of the respondents agree or strongly agree that they enjoyed using EDpuzzle to prepare for the class (see Figure 1).

Overall, I enjoyed using EDpuzzle to prepare for the class.

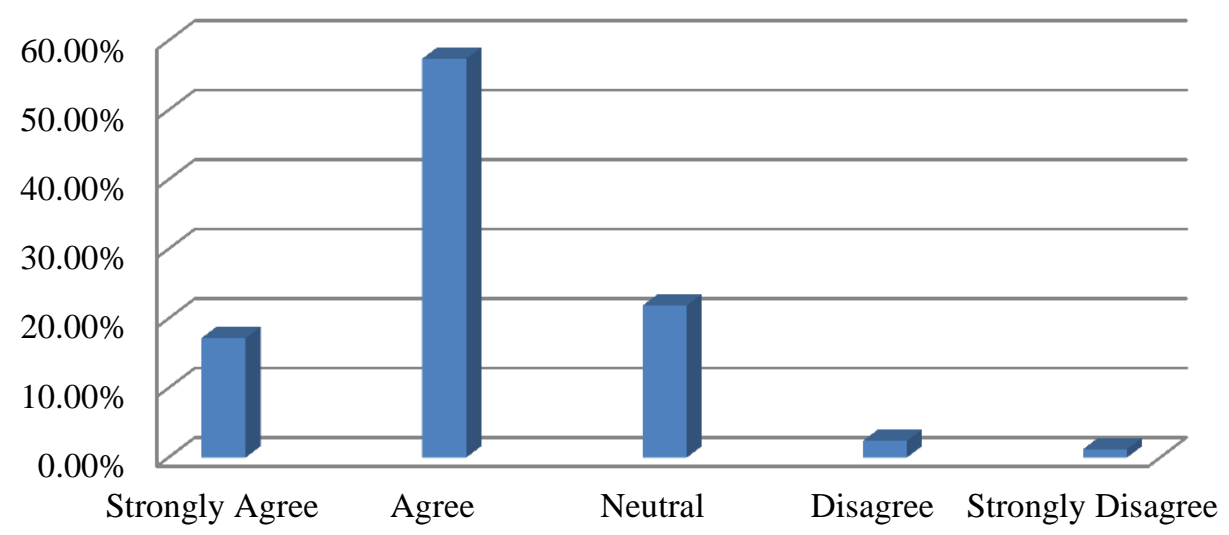

Figure 1. Students' overview of the use of EDpuzzle 
Among all the respondents, $136(80 \%)$ claimed that they watched the assigned videos before the lectures. (Note 6) However, if they were not assigned to do anything, only 58 (34.10\%) students would prepare themselves for the lecture they attended (see Table 1), which indicates that students need to be motivated and encouraged for pre-class participation and preparation.

Table 1. Students' perceptions toward the class preparation

\begin{tabular}{cccc}
\hline Statement & \multicolumn{3}{c}{ Responses } \\
\hline If you were NOT assigned to do anything, would you & Yes & No & Not Sure \\
prepare for the lecture you attended? & 58 & 55 & 57 \\
& $34.10 \%$ & $32.40 \%$ & $33.50 \%$
\end{tabular}

122 students agree or strongly agree that watching videos helped them prepare more for the lectures. The majority of students (128) believe that watching videos prior to class helped them better understand the concepts delivered in class (see Table 2).

Table 2. Students' perceptions toward watching videos prior to class

\begin{tabular}{|c|c|c|c|c|c|}
\hline \multirow{2}{*}{ Statement } & \multicolumn{5}{|c|}{ Responses } \\
\hline & $\begin{array}{l}\text { Strongly } \\
\text { Agree }\end{array}$ & Agree & Neutral & Disagree & $\begin{array}{l}\text { Strongly } \\
\text { Disagree }\end{array}$ \\
\hline \multirow{2}{*}{$\begin{array}{l}\text { Watching videos helped me prepare more } \\
\text { for the lectures. }\end{array}$} & 29 & 93 & 47 & - & 1 \\
\hline & $17.06 \%$ & $54.71 \%$ & $27.65 \%$ & - & $0.59 \%$ \\
\hline \multirow{2}{*}{$\begin{array}{l}\text { Watching the videos before the lectures } \\
\text { helped me better understand the concepts } \\
\text { delivered in class. }\end{array}$} & 30 & 98 & 40 & 1 & 1 \\
\hline & $17.65 \%$ & $57.65 \%$ & $23.53 \%$ & $0.59 \%$ & $0.59 \%$ \\
\hline
\end{tabular}

We attribute this to the fact that the majority of the students (114) found it helpful to watch videos because they could repeatedly listen to the parts that they did not fully understand (see Figure 2).

It was helpful to watch the videos because I could repeatedly listen to the parts that I did not fully understand.

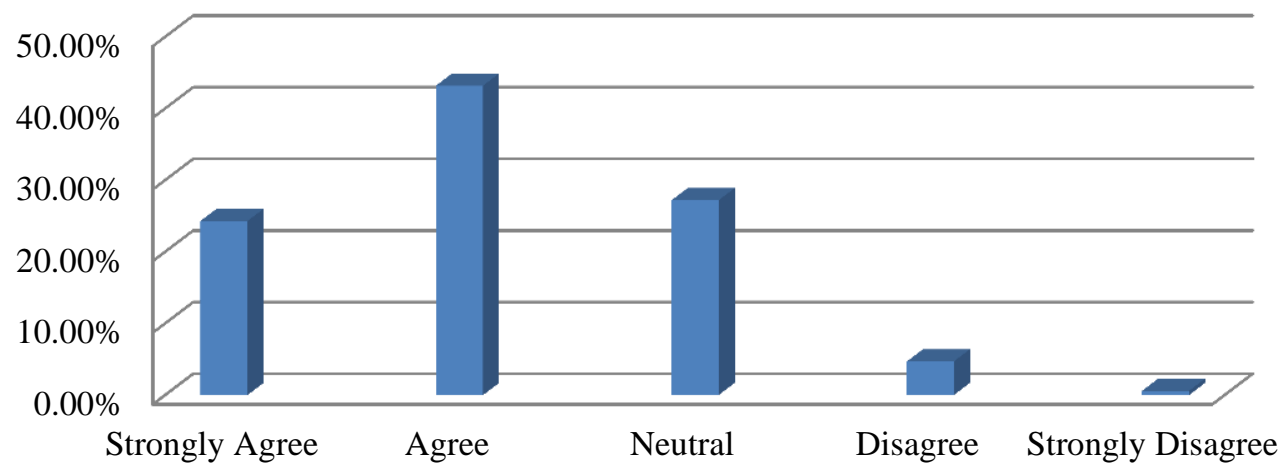

Figure 2. Students' perceptions toward watching videos 
Being able to watch videos repeatedly is particularly helpful to the non-majors who may need more instructions and explanations on even basic concepts. That may also be the reason why most of the students believe that having lectures recorded would benefit them as a student (see Figure 3). (Note 7)

\section{I think that having lectures recorded would benefit me as a student.}

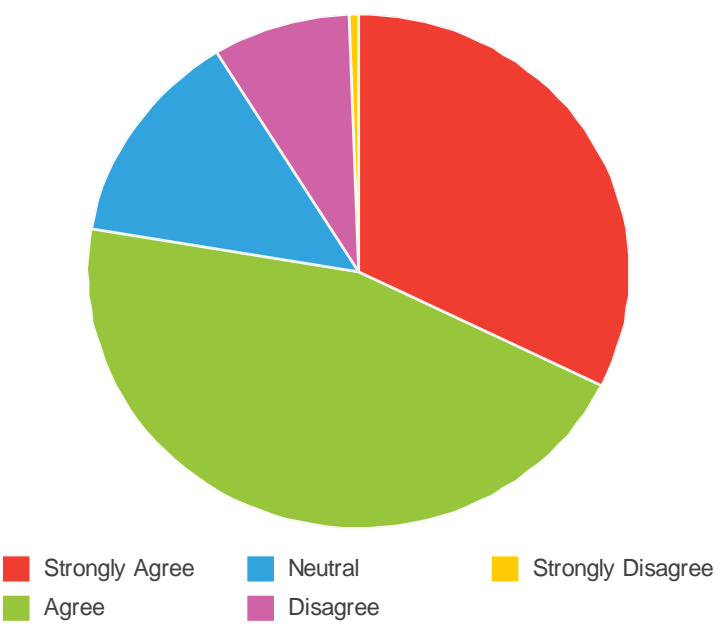

Figure 3. Students' perceptions toward recorded lectures

In addition, only $16 \%$ of the students complained it was burdensome to watch the videos as they felt under an obligation to study in addition to the class (see Figure 4).

It was burdensome to watch the videos as I was under an obligation to study in addition to the class.

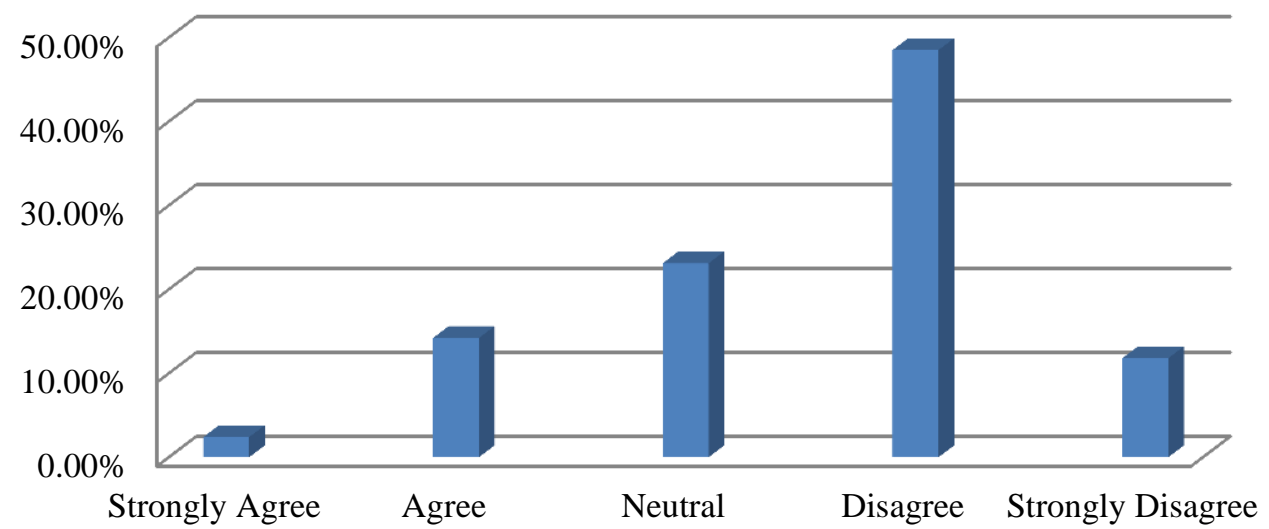

Figure 4. Students' perceptions toward watching the videos outside of the class

In addition to using EDpuzzle to monitor students' preparation for a class, i.e. whether they have watched the video or not, a more effective way to motivate student participation may be to assign course credit to the homework. Approximately $70 \%$ of the students claimed that they would watch the videos for the sake of course credit (see Figure 5). 
I would watch the videos before the lectures if there was course credit assigned to them.

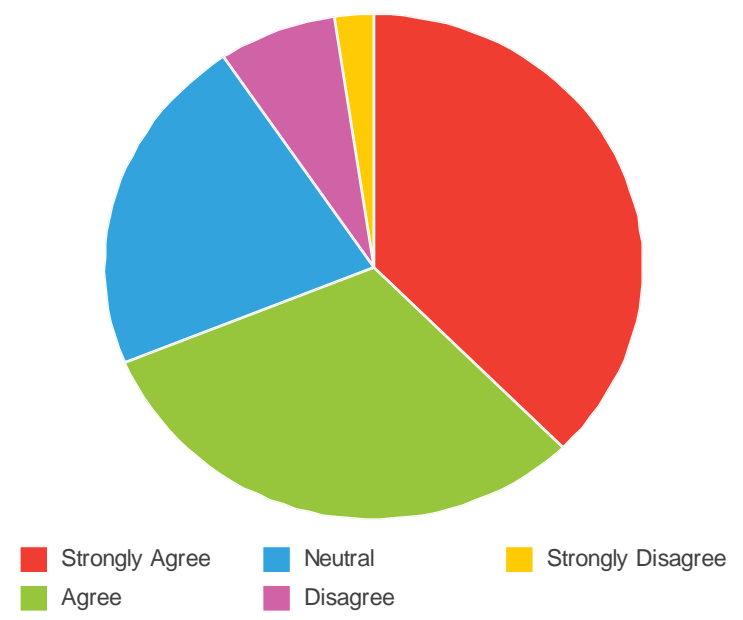

Figure 5. Students' responses if course credit assigned to watching videos

In the end, when the students were asked whether they would like to take a course using the flipped classroom design, the answers are not quite promising with only $47 \%$ of the students claimed that they would like to watch the recorded lecture and then have in-person interaction and problem solving exercises in class. This can be partially due to the fact that the flipped classroom is still brand new to students. In addition, the non-major students seem to be more reliant on lecturers for direct instruction and explanation when learning economics.

\section{Discussion}

We tracked the record of students' activities at home, i.e. whether or not they watched videos. To our disappointment, the actual usage of EDpuzzle tended to decline each week, despite the overall positive feedback from the students regarding the easy use of this online tool (see Figure 6).

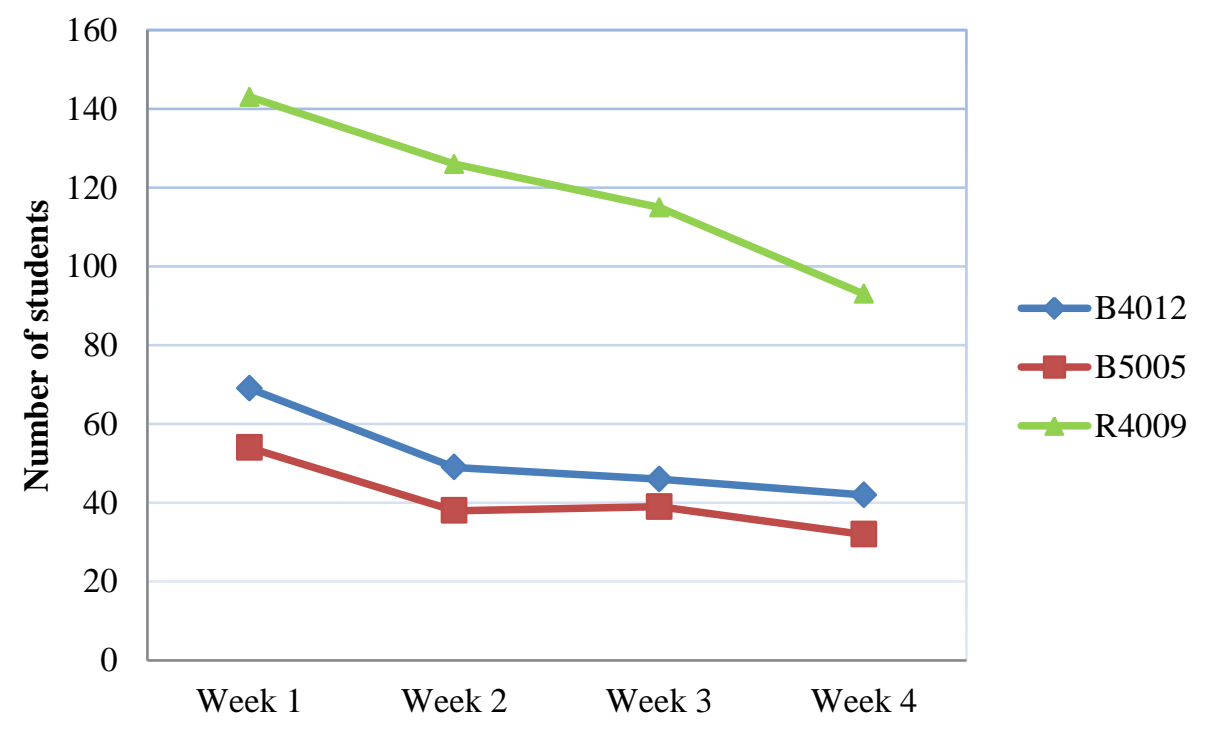

Figure 6. The number of students using EDpuzzle each week

The declining number of usage implies that insufficient motivation of the students to prepare for class is still a persistent issue. Because this is a pilot study on flipping the classroom, we did not recorded our entire lecture but used the related videos selected from online sources. Those videos were less like a traditional lecture but explained some concepts or included applications of economic theory. Students might not view these as part of the "formal" lecture, but take them as additional materials to the lecture. It might change students' attitude and preparation habits if the videos that they were required to watch were recorded lectures, which, however, needs to be further examined.

Although the students were required to watch the videos before each lecture and they knew their activities were 
monitored by the lecturers, in our trial it was of no consequence if they did not complete the homework ahead of time. The flipped classroom model, similar to other teaching methods, depends heavily on students preparing before coming to the class. Watching videos is a means of preparation. But if some students fail to do so, should the lecturer spend class time on going through the material in the video again? Clearly, the flipped classroom does not work anymore if that is the case. After all, the flipped classroom is designed to save class time that can be devoted to engage students in learning through active learning experience. As the student survey implies assigning course credit to the homework can be an easy solution, but the best way to improve students' participation is to get them interested in either the materials in the video or the application of the knowledge to the in-class activities. The practice of flipping involves the use of videos and design of activities. Technologies, like EDpuzzle, may be used to enhance delivery of instruction, but what is more important is how to best use the in-class time with students. As we only partially flipped our class, the students might not be able to fully understand the connection between pre-class preparation and in-class activities.

Admittedly, our lack of experience of using this new teaching technique may be another reason for students' losing their interest in watching videos. But we still see the potential of using the flipped classroom as it is revealed by the student survey that students do appreciate helpfulness of watching videos in terms of better preparation for the lectures and reinforcement of understanding.

\section{Conclusion}

Traditional teaching generally takes place in classrooms with most of the time allocated toward lecturing. Although a growing number of studies show that practice, active involvement and feedback are essential elements for student learning process, they are all constrained by the limited class time. As one of the solutions to the time constraint in a class, a new pedagogical approach called "flipped classroom" is proposed, which suggests to move course content from the classroom by asking students to watch the online videos or pre-recorded lectures before a class and then use class time for active exercises and engaging activities.

In our university, teaching economics poses a number of challenges, which reflect difficulties in presenting all necessary course materials during fifty-minute class time as the students are all non-economics majors and vary in levels of prior knowledge and understanding. Therefore, we feel that the flipped classroom can improve students' comprehension in the basic concepts and economic theory through the online video and come to the lecture with the same level of understanding so that they are able to actively engage in problem-solving activities in class.

In order to ensure that students do the preparation and watch the video prior to class, we adopted an online tool called "EDpuzzle", which can help lecturers track the record and monitor the class. As a pilot project, we only flipped a very small part of each class and surveyed 170 students at the end of four-week use of EDpuzzle. This trial helped us explore the possibility and potential to apply the flipped classroom in economics teaching at a wider scale.

When we talk about the flipped classroom, focus might be given to the production and use of the videos as well as the selection of the online videos. As a matter of fact, our experience tells us that the essence of a flipped classroom is not only the videos, but also the design of the active learning exercises and how to engage students in preparation prior to class. From our preliminary experience, we feel that flipped learning can be considered more of a complement, rather than a substitute (Roach, 2014), in particular, when teaching economics to non-majors who need more help from lecturers to understand the basic concepts. In addition, student feedback suggests that it is very helpful to watch those videos, however, the majority of students would not like to have the completely flipped classroom of watching the recorded lectures and then have in-person interaction and problem solving. We attribute this to the effect of partially flipping practice and our lack of experience in using such an innovative teaching and learning approach.

The flipped classroom instructional model is still relatively new, especially in the context of economics teaching. In addition, the study of teaching economics to non-economics students is of particular interest as evidence shows economics is now taught to a wide variety of students majoring in other disciplines like sciences, business and engineering as part of their programme requirement. As a matter of fact, the number of non-major students who take economics modules is much more than that of economics students (Islam \& Manaloor, 2012). Therefore, our study calls for further discussion and research on how we can design, apply and evaluate the flipped classroom in order to achieve effective teaching and learning economics for non-economics majors.

\section{Acknowledgements}

We would like to thank Dr Kun Wei for introducing EDpuzzle to us and the Department of Land, Farm and Agribusiness Management at Harper Adams University for being supportive to this research.

\section{References}

Abeysekera, L., \& Dawson, P. (2015). Motivation and cognitive load in the flipped classroom: Definition, rationale and a call for research. Higher Education Research \& Development, 34, 1-14. 
http://dx.doi.org/10.1080/07294360.2014.934336

Albert, M., \& Beatty, B. J. (2014). Flipping the classroom applications to curriculum redesign for an introduction to management course: Impact on grades. Journal of Education for Business, 89, 419-424. http://dx.doi.org/10.1080/08832323.2014.929559

Anderson, R., Anderson, R., Davis, P., Linnell, N., Prince, C., Razmov, V., \& Videon, F. (2007). Classroom presenter: Enhancing interactive education with Digital Ink. IEEE Computer, 40, 56-61. http://doi.ieeecomputersociety.org/10.1109/MC.2007.307

Asef-Vaziri, A. (2015). The flipped classroom of operations management: A not-for-cost-reduction platform. Decision Sciences Journal of Innovative Education, 13, 71-89. http://dx.doi.org/10.1111/dsji.12054

Bishoop, J. L., \& Verleger, M. (2013). The flipped classroom: A survey of the research. In ASEE National Conference Proceedings, Atlanta, GA. http://www.studiesuccesho.nl/wp-content/uploads/2014/04/flipped-classroom-artikel.pdf

Curdy, M. (2015). Summary report on the Nearpod pilot project. Retrieved from http://blogs.brighton.ac.uk/elearning/files/2015/06/NearpodPilotEvaluation-2gsmc4t.pdf

Dobson, J. (2008). The use of formative online quizzes to enhance class preparation and scores on summative exams. Advances in Physiology Education, 32, 297-302. http://dx.doi.org/10.1152/advan.90162.2008

Estes, M. D., Ingram, R., \& Liu, J. C. (2014). A review of flipped classroom research, practice, and technologies. International HETL Review, 4(7).

https://www.hetl.org/a-review-of-flipped-classroom-research-practice-and-technologies/

Goffe, W. L., \& Kauper, D. (2014). A survey of principles instructors: Why lecture prevails. The Journal of Economic Education, 45, 360-375. http://dx.doi.org/10.1080/00220485.2014.946547

Hamdan, N., McKnight, P., McKnight, K., \& Arfstrom, K. M. (2013). A review of flipped learning. Retrieved from http://www.flippedlearning.org/review

Islam, S., \& Manaloor, V. (2012). Teaching introductory economics to students of different majors: Challenges and opportunities, Journal of Higher Education Theory and Practice, 12(1), 56-65.

Johnson, B. C., \& Kiviniemi, M. T. (2009). The effect of online chapter quizzes on exam performance in an undergraduate social psychology course. Teaching of Psychology, 36, 33-37. http://dx.doi.org/10.1080/00986280802528972

Kadry, S., \& El Hami, A. (2014) Flipped classroom model in calculus II. Education, 4, 103-107. http://dx.doi.org/10.5923/j.edu.20140404.04

Mu, H., \& Paparas, D. (2015). Incorporating the advantages of clickers and mobile devices to teach economics to non-economists. Cogent Economics \& Finance, 3. http://dx.doi.org/10.1080/23322039.2015.1099802

Norman, S., \& Wills, D. (2015). Flipping your classroom in economics instruction: It's not all or nothing. Retrieved from http://faculty.washington.edu/normanse/uploads/2/9/8/5/29853431/flipping_your_classroom.pdf

Prashar, A. (2015). Assessing the flipped classroom in operations management: A pilot study. Journal of Education for Business, 90, 126-138. http://dx.doi.org/10.1080/08832323.2015.1007904

Roach, T. (2014). Student perceptions toward flipped learning: New methods to increase interaction and active learning in economics. International Review of Economics Education, 17, 74-84. http://dx.doi.org/10.1016/j.iree.2014.08.003

Sahin, A., Cavlazoglu, B., \& Zeytuncu, Y. E. (2015). Flipping a college calculus course: A case study. Educational Technology \& Society, 18, 142-152. Retrieved from http://www.ifets.info/journals/18_3/11.pdf

\section{Notes}

Note 1 . When signing up as a teacher, you will be given a brief tutorial of how to trim a video, insert a question and track the result.

Note 2. Students also have to set up free accounts to log-in, so that teachers can easily keep track of the result.

Note 3. This feature helps eliminate advertisements and keep the video length appropriate for the specific learning group if using the online sources.

Note 4. EDpuzzle allows students to go on watching the video even if students give the incorrect answer to the question.

Note 5. A disappointing fact about EDpuzzle is that lecturers cannot provide customized feedback to students for the 
multiple-choice questions except for correct/incorrect feedback option. In addition, there is no option to provide feedback to open-ended questions.

Note 6. For those students who claimed that they did not watch the assigned videos before the lectures, they were still asked to continue to answer the following questions because in Week 1 all the students were given a short tutorial of how to use EDpuzzle and had an opportunity to watch a trial video.

Note 7. In our trial we used online sources, not recorded lectures.

\section{(cc) EY}

This work is licensed under a Creative Commons Attribution 3.0 License. 